\title{
La "libertad de
}

\section{invertir" a la luz del}

caso argentino:

un análisis de los

Tratados Bilaterales

de Inversión*

/ The "Freedom to

Invest" in light of the

Argentinian case:

an analysis of Bilateral

Investment Treaties

* Recibido: 7 de febrero de 2014. Aceptado: 18 de marzo de 2014 .

Tla-Melaua, revista de Ciencias Sociales. Facultad de Derecho y Ciencias Sociales. Benemérita Universidad Autónoma de Puebla, México / issn: 1870-6916 / Nueva Época, Año 9, No 38, abril / septiembre 2015, pp. 24-44. 
RESUMEN

Este artículo se propone revisar el andamiaje legal internacional construido para garantizar la libre circulación de las inversiones, lo cual se ha vuelto central en el capitalismo contemporáneo, caracterizado por el comando del capital en su forma dineraria. Es así que en los últimos treinta años hemos asistido a una búsqueda creciente de protección del movimiento del dinero, generada a través de esquemas legales que sostienen la circulación irrestricta del capital a través de las fronteras estatales. En particular,aquí nos concentramos sobre los Tratados Bilaterales de Inversión (TBI). Dentro de estos, adquiere una importancia particular la cláusula de prórroga de jurisdicción, que permite a las empresas transnacionales demandar a los Estados en instancias supra-nacionales, como el Centro Internacional de Arreglo de Diferencias sobre Inversiones (CIADI).

PALABRAS CLAVE

Tratado Bilateral de Inversión, CIADI, teoría crítica,antagonismo social.
A BSTRACT

This article intends to review the international legal platform that has been established to guarantee the free circulation of investment, which has become a central issue in contemporary capitalism, characterized by the command of capital in its monetary form. Therefore, in the past thirty years, we have witnessed an growing search for protection of monetary movement generated through legal frameworks that support the unrestricted movement of capital across state borders. In particular, we will here focus on the Bilateral Investment Treaties (BIT). In these treaties, the clause of extension of jurisdiction has a particular importance. It allows transnational corporations to bring a law suit against states in supra-national bodies, such as the International Center for Settlement of Investment Disputes (ICSID).

KEYWORDS

Bilateral Treaty, ICSID, Gritic theory, Social Antagonism.

\footnotetext{
* Doctora en Ciencias Sociales. Universidad de Buenos Aires, Argentina. (luciana.ghiotto@gmail.com) 

circulación del capital / 3. Acerca de las inversiones (extranjeras y nacionales) / 4. La protección de las inversiones vía Centro Integral de Arreglo de Diferencias sobre Inversiones (CIADI) / 5. Los Tratados Bilaterales de Inversión (TBI) argentinos: cómo se protegen las inversiones / 6. Conclusiones

\section{INTRODUCC I ÓN}

Este artículo se propone revisar el andamiaje legal internacional construido para garantizar la libre circulación de las inversiones en el capitalismo contemporáneo. En este periodo, caracterizado por el comando del capital en su forma dineraria, la garantía para el libre flujo del dinero se ha vuelto central. Es así que en los últimos treinta años hemos asistido a una búsqueda creciente de protección del movimiento del dinero, la cual opera a través de esquemas legales que sostienen la circulación irrestricta del capital a través de las fronteras estatales. Mediante la expresión "nuevo andamiaje legal internacional" nos referimos a los diferentes tipos de tratados internacionales que incluyen cláusulas tendientes a garantizar la libertad del capital. En particular, aquí nos concentramos sobre los Tratados Bilaterales de Inversión (TBI). Dentro de éstos adquiere una importancia particular la cláusula de prórroga de jurisdicción, que permite a las empresas transnacionales demandar a los Estados en una instancia supra-nacional como el Centro Internacional de Arreglo de Diferencias sobre Inversiones (CIADI).

Sin embargo, nuestro punto de partida no son los tratados en sí mismos, ni el sistema de arbitraje internacional montado a partir de 1966 con la creación del CiADI. Más bien, nuestra argumentación invierte dicho punto de partida, convirtiendo a los tratados en el punto de llegada del análisis. ${ }^{1}$ Es decir, vamos a entender a las protecciones de la inversión como una forma legal de las relaciones sociales antagónicas sobre las cuales tal andamiaje se construye. ${ }^{2}$ Partimos del argumento de que la protección a las inversiones es expresión del antagonismo social. La garantía a la libre circulación del capital

\footnotetext{
${ }^{1}$ Aquí nos diferenciamos de los artículos que se centran en el estudio del funcionamiento del sistema de arbitraje como objeto de estudio, tal como fuera publicado en el número 32 (2012) de esta revista, en el artículo de Castrillón y Luna. Mismo si dicho tipo de estudios son relevantes, en tanto arrojan luz sobre los procedimientos del sistema de arbitraje, no pueden dar cuenta de la relevancia que reviste la prórroga de jurisdicción hacia una instancia supra-nacional en el marco del actual patrón de acumulación en el capitalismo contemporáneo. Para ello, debemos invertir el punto de partida, tal como proponemos en este artículo. ${ }^{2}$ Para el concepto de forma, véase Holloway, John, Cambiar el mundo sin tomar el poder; el significado de la revolución hoy, Buenos Aires, Herramienta, 2002; Bonefeld, Werner, Critical theory and the Critique of Political Economy: on Subversion and Negative Reason, London, Bloomsbury, 2014; Dinerstein, Ana, "Subjetividad: capital y la materialidad abstracta del poder (Foucault y el marxismo abierto)", en Borón (ed.) Teoría y filosofía política. La tradición clásica y las nuevas fronteras, Buenos Aires, Clacso-Eudeba, 1999.
} 
es un elemento central para el nuevo comando (inestable) del capital sobre el trabajo (el comando del capital-dinero). La nueva legalidad intenta, entonces, negar la incertidumbre producida por la naturaleza inestable de la relación social del capital, ${ }^{3}$ ya que cristaliza contractualmente el intento del capital por escapar de la lucha de clases. Pero dicha inestabilidad, manifiesta en la forma de crisis, es inherente al antagonismo social. Si el capital intenta fugarse del trabajo para sostener la acumulación, buscando a su vez certezas legales para la ganancia, no puede escaparse de la relación antagónica que le da forma.

Para comprender el modo en que opera la nueva legalidad internacional, nos centraremos en el caso argentino. Con ese fin, vamos a analizar algunos de los 55 tratados bilaterales de inversión (TBI) firmados por Argentina. ${ }^{4}$ Revisaremos la manera en que se define la categoría de inversión en los TBI, y repasaremos sus cláusulas (en especial las de "Trato nacional", "Trato de nación más favorecida", "Protección y seguridad plenas", "Cláusula de estabilización", "Requisitos de desempeño", "Duración con efecto residual" y "Solución de controversias"). Veremos que en esas cláusulas queda plasmado el intento del capital por negar la incertidumbre: el texto de cada tratado bilateral es una expresión de la búsqueda del capital de la libertad total.

\section{EL COMANDO DEL CAPITAL-DINERO Y LA LIBRE CIRCULACIÓN DEL CAPITAL}

En los últimos cuarenta años hemos observado un avance en la imposición de la disciplina de mercado sobre la clase trabajadora. A las luchas obreras, estudiantiles y sociales de los años sesenta y setenta, ${ }^{5}$ el capital respondió mediante un intento de alejarse de la insubordinación. Frente al estrangulamiento ganancial que el capital encontraba en la esfera productiva, comenzó el proceso masivo de metamorfosis en dinero líquido. Esto implicó una rápida expansión en las bolsas de comercio y la creación de fondos de inversión.

\footnotetext{
${ }^{3}$ Ghiotto, Luciana y Pascual, Rodrigo, "El CIADI y las inversiones: acerca de la necesidad de certezas", Realidad Económica, núm. 238, Buenos Aires, Argentina, 2008.

${ }^{4}$ De acuerdo con los datos oficiales del ciadi, Argentina ha firmado 58 tratados bilaterales de inversión, pero tres de ellos nunca fueron ratificados, por lo cual no entraron en vigencia. International Center for Settlement of Investment Disputes, Database for Investment Treaties. [Consulta: mayo, 2015]. Disponible en: https://icsid.worldbank.org/apps/ICSIDWEB/resources/Pages/BITDetails.aspx?state=ST4

${ }^{5}$ En estas dos décadas las luchas del trabajo (en sus múltiples formas) fueron aumentando de manera gradual hasta concentrar una gran cantidad de protestas y rebeliones en el período 1968-1971. Algunas de estas son: en el continente africano los procesos de descolonización; en Europa, el Mayo Francés, la Primavera de Praga, el Otoño Caliente italiano, las protestas de los estudiantes en Alemania, etcétera. En las Américas, se pueden ver el movimiento hippie de Estados Unidos y las protestas contra la guerra de Vietnam, las organizaciones revolucionarias de los afro-americanos (Black Panthers), el Cordobazo en Argentina (junto con el Rosariazo y el Correntinazo), la Revolución cubana, las revueltas estudiantiles en México plasmadas en la matanza de Tlatelolco, las huelgas del triángulo del "ABC paulista" en Brasil. También se debe agregar la Revolución cultural china de 1969. Asimismo, hay que incluir la segunda ola del movimiento feminista y el nacimiento de las organizaciones ecologistas.
} 
El disciplinamiento de los trabajadores se realizó especialmente mediante mecanismos monetario-financieros ${ }^{6}$ a partir de la política de escasez de dinero impuesta a nivel de los mercados internos. Se rompía así el círculo del período keynesiano de la segunda posguerra, marcado por el fácil acceso de los trabajadores al dinero (vía salarios). En el período neoliberal, el dinero escaso fue sostenido por políticas de liberalización de los movimientos del capital a nivel global. Esto conformó un nuevo patrón de acumulación y un nuevo comando sobre la clase trabajadora: el comando del capital-dinero. ${ }^{7}$ Este comando se sostiene sobre la conversión masiva del capital productivo en capital líquido y financiero. La libre circulación del capital, en su forma de inversiones, resulta central para sostener al capitalismo en su conjunto.

En este proceso se produjo una aparente disociación entre el dinero y el proceso de la acumulación. El capital-dinero asumió una "forma independiente", como si el interés (el "nuevo" dinero) surgiera de un lugar distinto al proceso productivo. Pero a pesar de que el capital-dinero se presenta como pura forma sin contenido, para poder sostener su comando sobre el trabajo debe lidiar con la lucha cotidiana por la extracción de plusvalor. Esto caracteriza al capital en su forma de capital-dinero. En los años setenta, la conversión masiva en capital-dinero significó una apuesta a futuro sobre la posibilidad concreta de explotar el trabajo en un momento posterior. ${ }^{8}$ Es decir, el capitaldinero adelantado (en forma de créditos y deuda) debería más adelante volver a convertirse en capital productivo para garantizar la efectiva explotación del trabajo. La separación implicó dejar para el futuro (el intento de) la resolución del "problema del trabajo". ${ }^{9}$ Mostraba así que la insubordinación del trabajo no podía ser frenada en el marco de las políticas keynesianas, pero que el monetarismo tampoco lograba sentar las bases para un nuevo y duradero patrón de acumulación de capital sin caer en crisis recurrentes.

El neoliberalismo condensa el nuevo patrón de acumulación del capital, construido sobre la liquidez del dinero y su libre flujo. Es así que el modo en que se produce esa circulación se ha vuelto central. En tanto se trata de un nuevo modo de imposición de disciplina sobre la clase trabajadora, se vuelve imperioso garantizar la libre circulación del capital. Si asumimos el carácter antagónico de las relaciones sociales capitalistas, debemos con ello

\footnotetext{
${ }^{6}$ Bonnet, Alberto, "Políticas neoliberales y lucha de clases", en Bonefeld, Bonnet, Holloway y Tischler (comps.), Marxismo Abierto II, una visión europea y latinoamericana, Buenos Aires, Herramienta, 2007.

${ }^{7}$ Bonefeld, Werner, "Monetarism and crisis", en Bonefeld y Holloway (comps.), Global Capital, National State and the Politics of Money, Londres, Macmillan Press, 1996; Bonnet, Alberto, "El comando del capital-dinero y las crisis latinoamericanas", en Bonefeld y Tischler (comps.), A 100 años del ¿Qué Hacer?: Leninismo, crítica marxista y la cuestión de la revolución hoy, Buenos Aires, Herramienta, 2003.

${ }^{8}$ Negri, Antonio, “John M. Keynes y la teoría capitalista del Estado en el '29”, en Negri, Antonio, Crisis de la política. Escritos sobre Marx, Keynes, las crisis capitalistas y las nuevas subjetividades, Buenos Aires, El cielo por asalto, 2003; Bonefeld, Werner, "Monetarism and crisis", op. cit.

${ }_{9}^{9}$ Holloway, John, "Surgimiento y caída del keynesianismo: se abre el abismo", en John Holloway, Keynesianismo, una peligrosa ilusión; un aporte al debate de la teoría de cambio social, Buenos Aires, Herramienta, 2003.
} 
comprender que el capital es una relación de crisis. ${ }^{10}$ Esto significa que la inseguridad del capital es interna a su constitución misma. Nunca podemos saber ex ante cómo se va a resolver una relación de antagonismo, de lucha, de enfrentamiento. De allí que el capital construya mecanismos que le permitan obtener ciertos niveles de certidumbre. Ese punto neurálgico del nuevo patrón de acumulación es el que abordamos en este artículo: la generación de garantías para el movimiento irrestricto de capitales a nivel global.

El capital no es aquí entendido como una cosa, sino como una relación social basada en la imposición del trabajo asalariado, es decir, de nuestro constante recrearnos como clase (trabajadora). ${ }^{11}$ En tanto que se construye sobre la imposición, sobre la subordinación, la relación del capital genera una sociedad antagónica. Esta imposición ha generado un tipo de libertad e igualdad que la relación del capital requiere para sostener su valorización: que seamos libres e iguales para vender nuestra fuerza de trabajo; esto es la libertad de mercado. Se trata de una libertad real, pero también abstracta, en tanto que estamos obligados a trabajar para sobrevivir. Entonces, de la libertad que hablamos aquí es la del capital como relación social: la libertad del libre contrato. La forma política que toma la relación antagónica entre trabajo y capital, el Estado, sostiene esa libertad contractual.

El hecho de que hoy el capital se mueva libremente por todo el mundo no implica que antes no lo hiciera, al menos como tendencia. Esa es su "naturaleza": la libre movilidad. En la segunda posguerra, los Estados erigieron diversas restricciones a la circulación del capital, generando un ámbito propicio para el desarrollo de las industrias nacionales, del "compre nacional". Debido a la incertidumbre acerca de la continuidad del propio sistema, el capital se mantuvo por largos períodos en territorios determinados. Por ello es también que se asocian ciertas empresas con algunos Estados-nación en particular (como podría ser Volkswagen con Alemania). En esa etapa, el tipo de capital predominante era el productivo, y sobre él se erigía un modo de acumulación basado en la demanda efectiva y el pleno empleo. Pero esos límites al capital eran la expresión, en los ámbitos político y económico, de la lucha del trabajo contra el capital. Esa lucha dio forma a un modo de acumulación que no llegó a durar siquiera los "treinta años gloriosos" auspiciados por sus defensores. A partir de los años setenta, tanto el capital como el trabajo pusieron en crisis el inestable equilibrio de posguerra y se rompió el patrón de acumulación particular del período keynesiano. La constitución del comando del capital-dinero es, en ese sentido, la expresión más acabada (hasta ahora) de la tendencia a la liberalización del capital.

\footnotetext{
${ }^{10}$ Holloway, John, Cambiar el mundo sin tomar el poder... op. cit.

${ }^{11}$ Ibidem. 


\section{ACERCA DE LAS INVERSiOnES (EXTRANJERAS Y NACIONALES )}

Nos concentramos en una de las formas que adopta el capital: las inversiones, especialmente aquello que se conoce como inversión extranjera directa (IED). En el capitalismo, la búsqueda de los capitalistas por la protección de sus inversiones ha sido históricamente primordial. Estos reclaman a los Estados "seguridad jurídica" con el fin de garantizar la inviolabilidad de la inversión y, con ello, la ganancia. Pero entonces, ¿qué es lo nuevo? Explicamos que el neoliberalismo cristalizó el nuevo momento de la relación antagónica entre capital y trabajo, donde la legislación protectora de los trabajadores típica del keynesianismo fue reemplazada por una legislación más acorde con las necesidades de libre circulación del capital. Esta nueva legislación tomó cuerpo en un nuevo andamiaje legal internacional que comenzó a operar masivamente a escala global a partir de los años noventa. ${ }^{12}$ Veamos ahora más de cerca este proceso.

Las legislaciones de los años de posguerra protegían los derechos sociales en tanto cristalización legal de la lucha de clases. Esto implica que las décadas de lucha (con el hito central de la Revolución rusa) lograron reorientar una pequeña porción de las ganancias hacia los trabajadores. Se reorientó una parte del dinero (centralmente vía impuestos), pero las leyes nacionales nunca dejaron de proteger los derechos de propiedad privada. De hecho, la integración ciudadana de los trabajadores dependió centralmente de la integración productiva del trabajo, plasmada en los acuerdos de productividad. ${ }^{13}$

Ya en el neoliberalismo, el comando del capital-dinero se expresó en una legalidad modificada, esta vez más claramente a favor del capital. El dinero comanda la acumulación del capital a través de la flexibilidad salarial, liberando al mercado de las rigideces de la negociación colectiva y de las leyes con altos estándares laborales. ${ }^{14}$ Esto llevó a un aumento espectacular en el costo de vida de los trabajadores.

A partir de los años noventa, las garantías al capital se expresaron no solamente en las leyes nacionales, sino también en una nueva legalidad internacional. El mundo neoliberal "desregulado" requiere de nuevas regulaciones que garanticen la imposición del trabajo. El ejemplo más cabal de dicha legalidad protectora de las inversiones está en los tratados bilaterales de inversión (TBI). En los años noventa se produjo una proliferación de estos tratados, ya que mientras en los años cincuenta existía sólo uno, en los noventa ya había 1857, de los cuales 1472 fueron firmados solamente en esta década. ${ }^{15}$

${ }^{12}$ Estay, Jaime y Sánchez, Germán, "Una revisión general del ALCA y sus implicaciones”, en Estay y Sánchez (comps.), El ALCA y sus peligros para América Latina, Buenos Aires. Clacso, 2005.

${ }^{13}$ Altamira, César, "Trabajo vivo, crisis y nuevos sujetos", 2002. [Consulta: septiembre, 2008]. Disponible en: www

${ }^{14}$ Bonefeld, "Monetarism and Crisis", op. cit.

${ }^{15}$ Estay, Jaime y Sánchez, Germán, op. cit. 
A su vez, en el mismo período se comenzaron a firmar tratados de libre comercio (TLC). El primero fue firmado en 1985 entre Estado Unidos e Israel. El segundo, entre Estados Unidos y Canadá en 1991; luego se amplió a México en 1994, conformando así el Tratado de Libre Comercio de América del Norte (TLGAN). Casi treinta años después, se encuentran vigentes 69 TLC, de tipo bilateral y multilateral. ${ }^{16}$ La característica común de estos acuerdos es que incluyen los llamados "nuevos temas comerciales" estipulados a partir de la Ronda Uruguay de la Organización Mundial de Comercio (OMC); es decir, amparan no sólo el comercio de bienes, sino también el comercio de servicios, inversiones, compras gubernamentales, agricultura, propiedad intelectual, telecomunicaciones, etcétera. ${ }^{17}$

La vía de los TBI es bilateral, pero también se avanzó en los noventa en un plano más amplio con el intento de cerrar un Acuerdo Multilateral de Inversiones (AMI), que resultó fallido. ${ }^{18}$ Éste procuraba abrir los mercados mundiales que aún estaban protegidos a las inversiones financieras. Por otra parte, existe actualmente un marco de medidas multilaterales sobre inversiones relativas al comercio en el marco de la oma (acuerdo conocido como Trims), que representa apenas un acuerdo base, un esqueleto, de aquello que más adelante podría ser un nuevo AMI global. ${ }^{19}$ De todos modos, las negociaciones en este ámbito se encuentran trabadas, al menos desde la Reunión Ministerial de la OMC en Cancún en 2003. ${ }^{20}$

En los países latinoamericanos, la protección casi irrestricta a las inversiones tomó cuerpo a partir del entendimiento de que el arribo de capitales extranjeros (vía préstamos, inversiones de cartera e inversión extranjera directa) provocaría el desarrollo y el crecimiento económicos. Para fomentar su llegada, se aplicó una política de "puertas abiertas". El apoyo a la llegada de capitales extranjeros se basó en la idea de que estos jugarían dos roles. Por un lado, compensarían el déficit en el ahorro nacional, permitiendo así

\footnotetext{
${ }^{16}$ Es decir, existen tratados firmados por sólo dos países, mientras que otros involucran a varias decenas, como es el caso del TLC entre la Unión Europea y los países centroamericanos, firmado en total por 44 países. Cabe señalar que los tratados firmados por la Unión Europea no llevan el nombre de TLC, sino que son Acuerdos de Sociedad Económica (Economic Partnership Agreement, EPA), aunque poseen las mismas disposiciones, con el agregado de algunos capítulos de cooperación para el desarrollo económico y sustentable.

${ }^{17}$ Echaide, Javier y Ghiotto, Luciana, “La omc y la Ronda de Doha: ¿muerte y resurrección?”, Realidad Económica, núm. 226, Buenos Aires, 2006.

${ }^{18} \mathrm{El}$ AMI fue negociado en secreto entre los países de la Organización para la Cooperación y el Desarrollo Económico (OCDE) entre 1995 y 1998, cuando las negociaciones debieron ser frenadas, porque el contenido del acuerdo se filtró a las organizaciones sociales y por desacuerdos entre los propios Estados negociantes.

${ }^{19}$ Echaide, Javier y Ghiotto, Luciana, ¿Qué es el libre comercio? Entre mitos y realidades, Buenos Aires, Capital Intelectual, 2008.

${ }^{20}$ Se puede suponer que si entre los treinta países de la OCDE resultó imposible cerrar un acuerdo de liberalización en el área de inversiones (el AMI), más difícil es llegar a un acuerdo entre los 155 países miembro.
} 
el financiamiento de la actividad económica, aportando divisas y generando crecimiento económico; por otro, el libre flujo de estos capitales ayudaría a modernizar las economías, concretando el uso de nuevas tecnologías y aumentando la competitividad y la eficiencia frente a los capitales locales más parasitarios. Estas dos vertientes permitirían la inserción internacional de los países como exportadores. ${ }^{21}$ Sin embargo, la llegada de estos capitales extranjeros no garantizó el desarrollo económico interno, sino que profundizó la dependencia de los países al comercio exterior, y sujetó las economías nacionales al vaivén del escenario internacional.

\section{LA PROTECCIÓN DE LAS INVERSiONES VÍA CENTRO Integral DE ARREgLO DE Diferencias SOBRe InVERsiones ( C I ADI )}

Hemos explicado que la protección a las inversiones se hace efectiva hoy principalmente en el ámbito bilateral, al estilo тві, о multilateral de pequeña escala, como en los TLC. ${ }^{22}$ Lo que no se pudo avanzar con los grandes tratados de libre comercio en los años noventa (como con el fallido ALCA), se firmó más rápidamente vía TBI, ${ }^{23}$ es decir, protegiendo la circulación del capital en su forma de inversión extranjera directa. ${ }^{24}$ Por ejemplo, Argentina no ha firmado directamente ningún tratado de libre comercio, ${ }^{25}$ pero sí tiene 55 tratados bilaterales de inversión que protegen el comercio de inversiones y a las inversiones en sí mismas. Lo importante aquí es resaltar que los TLC y los тві no son cosas necesariamente distintas. Los tratados bilaterales tratan directamente sobre inversiones, mientras que los de libre comercio incluyen, además del capítulo sobre inversiones, los "nuevos temas comerciales".

\footnotetext{
${ }^{21}$ Estay, Jaime, "La inserción de América Latina en el actual orden internacional: crisis y alternativas", en Estay y Gambina (comps.), ¿Hacia dónde va el sistema mundial? Impactos y alternativas para América Latina y el Caribe, Buenos Aires, Redem-Fisyp-Clacso, 2007.

${ }^{22}$ Con "pequeña escala" nos referimos a que la mayoría de los TLC firmados en la primera década del siglo XXI son también bilaterales o multilaterales pero con países pertenecientes a una misma región geográfica, como los EPA impulsados por la UE con los países africanos o los TLC empujados por Estados Unidos con los asiáticos.

${ }^{23}$ Los tratados bilaterales de inversión, en su mayoría, no superan las siete u ocho páginas de extensión. Por su parte, el capítulo XI sobre inversiones del TLCAN cuenta con aproximadamente veintiún páginas, a la vez que el capítulo XVII sobre inversiones del tercer borrador del ALCA tiene cerca de 58 páginas (versión preliminar y en negociación).

${ }^{24}$ Los países con mayor cantidad de tratados bilaterales firmados son: Alemania (147), Suiza (127), Holanda (105), Francia (103), Reino Unido (102), Rumania (84), Italia (83), Egipto (91), República Checa (79), Bélgica-Luxemburgo (77), Corea del Sur (68), India y España (61). International Center for Settlement of Investment Disputes, Cases. [Consulta: septiembre, 2012]. Disponible en https://icsid. worldbank.org/ICSID

${ }^{25}$ La Argentina sólo ha firmado Tlc en el marco del Mercosur con países como Egipto, Marruecos e Israel. No obstante, dichos acuerdos no contienen todas las cláusulas tradicionales de los TLC; tampoco aparece allí la solución de controversias inversor-Estado, ni remiten al CIADI para la solución de disputas.
} 
En ambos casos se expresa el comando del capital-dinero, en tanto que las inversiones son tratadas y protegidas al igual que el comercio de bienes. Esto es una novedad de los últimos treinta años. La circulación del capital ya no es entendida solamente como de productos tangibles, sino que el comercio es también del propio capital en su forma de IED.

La mayoría de estos acuerdos, tanto los TLG como los TBI, tienen otra cuestión en común. Impulsan la apelación a un particular mecanismo de solución de controversias: el Centro Internacional de Arreglo de Diferencias sobre Inversiones (CIADI). Éste fue creado en 1966, y tiene su sede en Washington (aunque también funciona en París). Entró en vigor ese año con la suscripción del Convenio que dio nacimiento al CiADI por parte de veinte países. Para el año 2015, ya son 159 los que han suscrito el Convenio. ${ }^{26}$ El CiAdi opera dentro de la esfera del grupo del Banco Mundial, aunque se trata de una organización autónoma. Tiene como finalidad ser un centro de tribunales arbitrales para resolver cuestiones de contratos privados sobre inversiones. Esto quiere decir que constituye un ámbito donde se puede judicializar disputas contra un Estado por parte de los inversores, siempre en caso de que el Estado en cuestión haya suscrito un TLC o TBI con el Estado de donde ese capital es originario.

En el CIADI, cada caso es resuelto por un tribunal especialmente constituido para esa única cuestión. Está compuesto por tres árbitros: uno elegido por el demandante, otro por el demandado, y el tercero por ambas partes en común acuerdo. Este último será quien presida el tribunal. El hecho de que las partes elijan a quienes resolverán la cuestión pretende otorgar un halo de transparencia y de "igualdad de defensa en juicio". No obstante, estos no operan como "defensores" de la parte que los ha elegido. No es extraño encontrar casos en los cuales un tribunal arbitral decide unánimemente en contra de una de las partes, aun si uno de ellos "representa" a la parte perdedora. ${ }^{27}$

Siendo que el CIADI se apoya exclusivamente en los tratados que le otorgan jurisdicción para la resolución de conflictos (TBI y TLC), y que otorga protección y privilegios a las inversiones transnacionales sobre cualquier otro derecho establecido, normalmente se lauda en contra del Estado demandado. Los laudos del CIADI son comunicados a las partes litigantes aclarando también en qué forma se llegó a dicha resolución, de manera unánime o por mayoría. Sin embargo, no se aclara cómo votaron los árbitros, y mucho menos se permiten las expresiones en disidencia de alguno de ellos, algo que sí es común

\footnotetext{
${ }^{26}$ Cabe señalar que al firmarse el convenio del CIADI en los años sesenta, los países latinoamericanos se opusieron tajantemente. Sólo en los años ochenta, la mayoría suscribió el convenio.

${ }^{27}$ Echaide, Javier, "Aspectos jurídicos del ALCA y del sistema multilateral de comercio", en Gambina (comp.), Moloch siglo XXI; a propósito del imperialismo y las cumbres, Buenos Aires, Ediciones del Centro Cultural de la Cooperación, 2005.
} 
en las instancias judiciales nacionales. Otra de las cuestiones destacables es la falta de instancias superiores al tribunal arbitral que tengan potestad revisora sobre las decisiones de éste. Es decir, una segunda instancia u órgano de apelación. Entonces, los laudos del ciaDi son inapelables, y sus decisiones de fondo no son revisables.

La apelación al CIADI implica un cambio rotundo en los modos en que se imparte justicia al interior de los territorios nacionales. Se trata de una forma legal que ha sorteado los preceptos de las constituciones nacionales. Para algunos autores, la apelación al CIADI implica de hecho una privatización de la justicia. ${ }^{28}$ Anteriormente, los mecanismos de solución de controversias supranacionales eran para los Estados, es decir, Estado versus Estado, ambos con el mismo estatus jurídico internacional. A partir de la entrada en vigencia del CIADI, las empresas transnacionales se volvieron sujetos de derecho internacional; ${ }^{29}$ ahora se puede demandar a los Estados en el ámbito internacional, prerrogativa anteriormente sostenida para los Estados. Asimismo, la prórroga de jurisdicción hacia el CIADI implica el abandono de la doctrina Calvo. Esta doctrina, defendida por los países latinoamericanos a fines del siglo XIx, implica la obligada sujeción de los extranjeros a las leyes y jueces nacionales. También cabe decir que la apelación al CIADI es violatoria de la Carta de la Organización de los Estados Americanos y de la Carta de las Naciones Unidas. El CIADI, asimismo, estaría generando una nueva deuda externa, ya que se trata de demandas multimillonarias. ${ }^{30}$

En definitiva, el CIADI cristaliza jurídicamente la búsqueda de certezas por parte del capital. Efectivamente, la prórroga de jurisdicción le permite a las empresas contar con una modalidad particular de demanda frente a los Estados. Claro, no es nuevo el hecho de que una empresa (un privado) pueda demandar al poder público de un territorio determinado (un Estado). Pero, usualmente, quien garantiza la inversión (la propiedad) es la jurisdicción local nacional. Lo novedoso aquí es la instancia supranacional que se abre con la existencia de organismos como el CIADI. El CIADI aparece como el "guardián internacional" de las inversiones, amparado a partir de la firma de miles de TBI (y decenas de TLC) a lo largo y ancho del planeta.

\footnotetext{
${ }^{28}$ Corti, Arístides, "Acerca de la inmunidad del Estado frente a los tribunales arbitrales y judiciales externos (CIADI y otros)", Realidad Económica, núm. 211, Buenos Aires, 2005; Teitelbaum, Alejandro, "El CIADI y otros tribunales arbitrales internacionales", en AA.VV., Soberanía de los pueblos o intereses empresariales; los mecanismos de arreglos de diferencias Inversor-Estado y sus impactos sobre los derechos humanos y el ambiente, La Paz, Argentina, Fundación Solón-Redes-Amigos de la Tierra, 2008.

${ }^{29}$ Arroyo, Alberto, "El origen de los derechos de los inversionistas que defiende el ciADI", en AA.VV., Soberanía de los pueblos o intereses empresariales; los mecanismos de arreglos de diferencias Inversor-Estado y sus impactos sobre los derechos humanos y el ambiente, La Paz, Argentina, Fundación Solón-Redes-Amigos de la Tierra, 2008.

${ }^{30}$ Costante, Liliana, "El ciadi como herramienta de consolidación de la dependencia. Caso Argentina", en Estay y Gambina (comps.), ¿Hacia dónde va el sistema mundial? Impactos y alternativas para América Latina y el Caribe, Buenos Aires, Redem-Fisyp-Clacso, 2007.
} 


\section{LOS TRATAdOS Bilaterales de InVERsión (TBi) ARGENTINOS : CÓMO SE PROTEGEN LAS INVERSIONES}

Vamos ahora a abordar las condiciones contractuales de los TBI, para ver así cuáles son las garantías que tienen hoy los capitales a partir de estos tratados. Aclaramos que el énfasis estará puesto sobre los TBI firmados por Argentina, con el fin de observar en un caso concreto el modo en que operan estas condiciones contractuales. ${ }^{31}$

Primero veamos: ¿cómo definen los TBI qué es una inversión? De acuerdo con el твI entre Argentina y Dinamarca, la inversión es:

(a) la propiedad de bienes muebles e inmuebles así como cualquier otro derecho real respecto de todo tipo de activo;

(b) acciones, derechos de participación en sociedades y otros tipos de participaciones en sociedades y empresas conjuntas;

(c) títulos y acreencias o cualquier otro derecho a una prestación que tenga valor económico; los préstamos solamente estarán comprendidos cuando estén directamente relacionados a una inversión específica;

(d) derechos de propiedad intelectual, incluyendo en particular derechos de autor, patentes, diseños industriales, marcas, nombres comerciales, procedimientos técnicos, transferencia de conocimientos y valor llave;

(e) concesiones económicas conferidas por ley o por contrato, incluyendo las concesiones para la prospección, cultivo, extracción o explotación de recursos naturales;

(f) ganancias que se hayan reinvertido. ${ }^{32}$

Es interesante analizar algunos de estos puntos incluidos en la definición de inversión. Por ejemplo, el punto (d) comprende los derechos de propiedad intelectual como parte de la inversión. Este punto ha sido crucial para avalar la demanda de la multinacional tabacalera Philip Morris versus Uruguay en marzo de 2010..$^{33}$ La cláusula de derechos de propiedad intelectual comprende

\footnotetext{
${ }^{31}$ En este apartado trabajaremos especialmente sobre los TBI firmados con Dinamarca, Panamá, Estados Unidos, Alemania, China, Canadá, Italia y Francia. La selección responde al interés por mostrar que las condiciones contractuales de los tratados bilaterales se dan en todos por igual, más allá del país del cual se trate. En particular, interesa desarmar la idea de que las peores condiciones son con los llamados "países imperialistas", como Estados Unidos. De hecho, veremos que el tratado con Panamá plantea algunas condiciones más duras.

${ }^{32}$ Acuerdo suscrito con el Gobierno del Reino de Dinamarca para la Promoción y Protección Recíproca de Inversiones, artículo 1, 1994.

${ }^{33}$ La Philip Morris se amparó del тві entre Uruguay y Suiza, argumentando que la política del Estado uruguayo tendiente a concientizar a la población acerca de los perjuicios del cigarrillo lesionó sus intereses expropiando su propiedad intelectual sin compensaciones, no fue tratada de forma justa y equitativa y que la aplicación de las mismas le provocarían una pérdida sustancial del mercado. Por estos conceptos reclama al Uruguay una reparación económica de dos mil millones de dólares.
} 
la transferencia de conocimientos y procedimientos técnicos. Por tanto, una transnacional puede obtener un conocimiento en el territorio de una de las partes (por ejemplo, del saber ancestral de los pueblos originarios) y patentarlo, sin siquiera transferir el conocimiento a esa parte.

Otro punto por resaltar de esta definición es que se haga explícita referencia a las concesiones para la explotación de recursos naturales. Esta especificación no aparece en todos los TBI, pero sí en el tratado entre Argentina y Dinamarca, además de los firmados con España, Canadá, China, Italia y Francia, entre otros. No es casual que se incluya la explotación de recursos naturales, si pensamos que en los años noventa, a partir de la privatización de los servicios públicos, la explotación y el servicio de provisión del agua, del gas, de la energía eléctrica y el petróleo, entre otros, pasaron a ser concesionados a empresas privadas, en su mayoría empresas transnacionales provenientes de varios de los países con los que la Argentina firmó tratados bilaterales de inversión.

Además de estos puntos, en el tratado bilateral entre Argentina y España se agrega también: "Ninguna modificación de la forma jurídica según la cual los activos y capitales hayan sido invertidos o reinvertidos deberá afectar su calificación de inversiones de acuerdo con el presente Acuerdo"; es decir, ninguno de los países firmantes puede modificar la definición de inversión antes explicada.

La definición de inversión que estipulan los TBI es similar a la que aparece en los TLC. En todos los casos, la definición de inversión es tan amplia que incluye cualquier movimiento de capital. Por ejemplo, en el capítulo XI del Tratado de Libre Comercio de América del Norte (NAFTA, por sus siglas en inglés), una inversión incluye empresas, acciones de empresas, contratos, bienes raíces u otras propiedades (tangibles o intangibles). Del mismo modo, en el tercer borrador del fallido Área de Libre Comercio de las Américas (ALCA), la inversión es considerada todo tipo de bienes, derechos y activos de cualquier naturaleza adquiridos con recursos transferidos al territorio de un Estado por parte de inversionistas de otro: la creación o adquisición de una empresa, de acciones, de bienes muebles e inmuebles, derechos de propiedad intelectual, licencia para la exploración y explotación de recursos naturales, etcétera. ${ }^{34}$ Como vemos, cualquier movimiento del capital puede ser considerado una inversión, y está protegido por el paraguas de estos tratados.

En segundo lugar, revisamos la cláusula de Trato nacional, justo, equitativo y no discriminatorio. Esto implica que al inversor extranjero se le concede igual trato que a un inversor nacional. Si existen, por ejemplo, exenciones impositivas para los inversores nacionales, el Estado debe otorgar la misma

\footnotetext{
${ }^{34}$ En el borrador del ALCA, el capítulo sobre inversiones fue el más conflictivo, pues contenía la mayor cantidad de puntos donde no había acuerdo entre las partes. En lo que respecta a la definición de inversión, no había acuerdo acerca de la posibilidad de incluir en dicha definición al capital especulativo.
} 
exención a la inversión extranjera. El TBI entre Argentina y Dinamarca dice en su artículo tercero:

Con relación a los impuestos, tasas, cargas, deducciones fiscales y exenciones, cada Parte Contratante acordará a las inversiones realizadas en su territorio por inversores de la otra Parte Contratante un tratamiento no menos favorable que el que concede a sus propios inversores o a los inversores de un tercer Estado, cualquiera sea más favorable para el inversor concernido.

Entonces, no puede haber un trato diferenciado porque eso sería considerado discriminatorio; excepto, claro, que el trato especial sea en beneficio de la inversión, como un cobro de impuestos menor, con el fin de mantener la inversión en el territorio. El Estado se compromete, mediante estas cláusulas, a no interferir de ningún modo con la inversión y a facilitar el máximo posible su realización. Sobre esto, el твI entre Argentina y España afirma en su artículo tercero:

Cada Parte protegerá en su territorio las inversiones efectuadas, conforme a su legislación, o inversores de la otra Parte y no obstaculizará, mediante medidas injustificadas o discriminatorias, la gestión, el mantenimiento, la utilización, el disfrute, la extensión, la venta ni, en su caso, la liquidación de tales inversiones.

Asimismo, algunos TBI agregan la dimensión de libre circulación de empresarios vinculados con las inversiones. Mientras que en la mayoría de los casos no hay libre circulación de personas entre los Estados (se requieren visas y se limita la estadía turística a tres meses), los empresarios tienen la libertad de circulación garantizada (tal como el capital al que representan). Algo similar sucede con los países del Tratado de Libre Comercio de América del Norte (NAFTA, por sus siglas en inglés): resulta casi imposible para la generalidad de los ciudadanos mexicanos entrar a territorio estadounidense, pero los "hombres de negocios" tienen la libertad de entrada y permanencia en Estados Unidos (aunque con restricciones). ${ }^{35}$ Esta libertad para los empresarios se ve en el твI entre Argentina y China:

\footnotetext{
${ }^{35}$ Las restricciones son notorias en el caso del NAFTA. En el apéndice 1603.D.4, se plantea que "Estados Unidos aprobará anualmente, respecto de México, hasta 5500 solicitudes iniciales de entrada temporal presentadas por personas de México que pretendan realizar actividades de negocios a nivel profesional". A su vez, los hombres de negocios mexicanos deben, además de cumplir con los requerimientos migratorios, tener certificado de educación secundaria o universitaria y probar que su estadía en el territorio norteamericano será temporal. Ghiotto, Luciana, "El ALCA, un fruto de la relación capital-trabajo”, en Estay y Sánchez (comps.), El ALCA y sus peligros para América Latina, Buenos Aires, Clacso, 2005.
} 
Cada Parte Contratante acordará en su territorio ayuda y facilidades para la obtención de visas y permisos de trabajo a los inversores de la otra Parte Contratante en relación con las actividades asociadas con tales inversiones.

En tercer lugar, la cláusula de Trato de Nación Más Favorecida permite al inversor aprovechar las condiciones fijadas por otros tratados que pudieran ser más favorables para su inversión. Si un TBI firmado por una parte otorga determinados beneficios a un inversor de un Estado, también debe dar el mismo beneficio a un tercero con quien haya suscrito otro TBI. Esta cláusula generaliza las ventajas y crea un entramado de protecciones donde el objetivo es siempre la mayor liberalización. El TBI entre Argentina y Alemania dice en su tercer artículo:

Ninguna de las Partes Contratantes someterá en su territorio a las inversiones de nacionales o sociedades de la otra Parte Contratante $[\ldots]$ a un trato menos favorable que el que se conceda a las inversiones de los propios nacionales y sociedades o a las inversiones de nacionales y sociedades de terceros Estados.

Sobre lo mismo, el TBI entre Argentina y Canadá explica:

Cuando una cuestión esté contemplada tanto por las disposiciones de este Convenio como por algún otro acuerdo internacional vinculante para ambas Partes Contratantes, nada de este Convenio impedirá que un inversor de una Parte Contratante que tenga inversiones en el territorio de la otra Parte Contratante se beneficie con el régimen más favorable.

Las cláusulas de Trato nacional y de Nación más favorecida se basan en el supuesto de que la competencia es en sí misma buena, por lo cual hay que garantizar la libertad total de acción de los actores "racionales" de la economía, sean o no nacionales.

En cuarto lugar, agrupamos las cláusulas que tratan la protección y seguridad plenas. Los TBI se refieren a las expropiaciones directas, las cuales implican una indemnización inmediata. El TBI entre Argentina y Alemania expone en el cuarto artículo:

Las inversiones de nacionales o sociedades de una de las Partes Contratantes no podrán, en el territorio de la otra Parte Contratante, ser expropiadas, nacionalizadas, o sometidas a otras medidas que en sus efectos equivalgan a expropiación o nacionalización, salvo por causas 
de utilidad pública, y deberán en tal caso ser indemnizadas. La indemnización deberá corresponder al valor de la inversión expropiada inmediatamente antes de la fecha de hacerse pública la expropiación efectiva o inminente, la nacionalización o la medida equivalente. La indemnización deberá abonarse sin demora y devengará intereses hasta la fecha de su pago según el tipo usual de interés bancario; deberá ser efectivamente realizable y libremente transferible.

Pero también refieren a la "expropiación indirecta", interpretada como la puesta en marcha de reglamentaciones de un Estado que reduzcan significativamente el valor de la inversión extranjera. Sobre esto, el TBI entre Argentina y los Estados Unidos expone que:

Las inversiones no se expropiarán o nacionalizarán directamente, ni indirectamente mediante la aplicación de medidas equivalentes a la expropiación o nacionalización (“expropiación”), salvo por razones de utilidad pública, de manera no discriminatoria y mediante pago de una compensación pronta, adecuada y efectiva, y de conformidad con el debido procedimiento legal.

Un problema que se vislumbra aquí es la laxitud del término "por razones de utilidad pública”. ¿Qué política puede ser considerada de utilidad pública? ¿La intervención en un momento de crisis política y económica, como en Argentina en 2002? Evidentemente, no. Estas cláusulas condenan las "medidas expropiatorias", como podrían ser ciertas normas de protección del medio ambiente (como en el caso de la demanda de la empresa minera Pacific Rim vs. El Salvador) o reglamentación de protección de la salud que afecten una inversión determinada (Philip Morris vs. Uruguay, como ya señalamos), o cambios en la política económica de un país (como en las demandas contra Argentina tras la devaluación en 2002). Estas cláusulas posibilitan incluso la compensación por pérdidas de ganancias futuras o esperadas por un inversor. En realidad, cualquier medida del Estado puede ser considerada como expropiatoria.

La seguridad plena incluye también la garantía a la total libertad de transferencia de las ganancias. Así, el твI entre Argentina y España dice en su artículo sexto: "Cada Parte otorgará a los inversores de la otra Parte, con respecto a las inversiones realizadas en su territorio, la posibilidad de transferir libremente las rentas o ganancias y otros pagos relacionados con las inversiones". Esto significa que las empresas transnacionales tienen total libertad de transferencia de los montos relativos a la inversión (compensaciones, ganancias, pagos, regalías, aportes de capital, salarios, liquidaciones, etcétera), ya sea en el interior del país receptor, o hacia el país desde donde se emitió la inversión. 
En quinto lugar, veamos la cláusula de estabilización. Esta cláusula hace referencia a que ambas partes se comprometen a no modificar las condiciones contractuales y jurídicas para la inversión; en caso de que se hiciera, esto no afectará los intereses privados. Así lo expresa el TВI entre Argentina y España:

Cada Parte protegerá en su territorio las inversiones efectuadas, conforme a su legislación, o inversores de la otra Parte y no obstaculizará, mediante medidas injustificadas o discriminatorias, la gestión, el mantenimiento, la utilización, el disfrute, la extensión, la venta ni, en su caso, la liquidación de tales inversiones.

Esto se basa en el principio de inmutabilidad de los contratos del derecho internacional y compromete al Estado a no aplicar medidas que perjudiquen los intereses de los privados. Una cláusula similar figura en el NAFTA, donde se protege a las inversiones incluso de una devaluación o fluctuación monetaria, ya que el pago es en equivalencia a una moneda de los países del G-7 (los siete países más industrializados). ${ }^{36} \mathrm{El}$ amparo de este tipo de cláusulas ha generado la mayor cantidad de demandas de transnacionales contra la Argentina tras la devaluación en 2002. Varias empresas interpretaron esta medida, junto con el congelamiento de las tarifas de los servicios públicos, como una violación de sus derechos protegidos por los TBI, y demandaron a la Argentina frente al CIADI. ${ }^{37}$

En sexto lugar, veamos los llamados Requisitos de desempeño. En los TBI se menciona de diversas maneras la incapacidad de las partes de imponer requisitos para el desempeño de la inversión en el territorio. Anteriormente, estos requisitos se utilizaban como modo de protección de la economía de un país; por ejemplo, las leyes del "compre nacional". Pero en los TBI esto no figura, o en algunos casos queda expresamente prohibido. El TBI entre Argentina y Estados Unidos deja en claro que:

Ninguna de las Partes establecerá requisitos de desempeño como condición para el establecimiento, la expansión o el mantenimiento de las inversiones, que requieran o exijan compromisos de exportar mercancías, o especifiquen que ciertas mercaderías o servicios se adquieran localmente, o impongan cualesquiera otros requisitos similares.

\footnotetext{
${ }^{36}$ Arroyo, Alberto, op. cit.

${ }^{37}$ Las empresas del sector energético, de aguas y saneamiento, y de telecomunicaciones que demandaron a la Argentina en 2003 fueron: Camuzzi, Gas Natural, AEs, Electricité de France, Endesa, Pan American Energy, El Paso Energy, Suez, Aguas de Barcelona y Telefónica de España. En el año 2004 lo hicieron Total, BP America, Wintershall, Mobil (petroleras) y Telecom. En el 2005, lo hizo la Compañía General de Electricidad de Chile (véase Ortiz, Ricardo, "Los tratados bilaterales de inversiones y las demandas en el CIADI: la experiencia argentina a comienzos del siglo XxI", documento de trabajo de Foco, 2006. Disponible en http://www.foco.org.ar/documentos-de-trabajo.htm). Algunas de las demandas interpuestas fueron posteriormente levantadas a partir de acuerdos con el Estado argentino; tal es el caso de Telefónica. La empresa demandó al país por 2834 millones de dólares, pero finalmente retiró la demanda tras obtener a cambio el ajuste de tarifas para las llamadas realizadas entre las 20 y las 21 horas, así como la dolarización de las comunicaciones que llegan a la Argentina desde el exterior.
} 
Esta cláusula incluye la no exigencia de que los empleados que ejecuten la inversión o los insumos utilizados para la misma sean nacionales del país receptor. De hecho, como vemos, nada puede ser exigido sobre la inversión.

En séptimo lugar, resaltamos las cláusulas que establecen una duración con efecto residual de los TBI. Estas cláusulas implican que se prolonga la protección sobre las inversiones, mismo si el tratado ya no tiene efecto o si el país ya no es signatario del Convenio del CIADI. La mayoría de los TBI duran diez años o más; pero continúan aplicándose por un plazo de diez o quince años, incluso si el TBI ya no está vigente. Asimismo, los TBI duran en promedio diez años, pero se renuevan automáticamente salvo que sean denunciados por alguno de los poderes en cualquiera de las partes. El TBI entre Argentina y Estados Unidos expone en su artículo catorce que:

Cada Parte podrá denunciar el presente Tratado al concluir el período inicial de diez años, o en cualquier momento posterior, por medio de notificación por escrito a la otra Parte con un año de antelación. Con respecto a las inversiones efectuadas o adquiridas con anterioridad a la fecha de terminación del presente Tratado [...], las disposiciones de todos los demás artículos del Tratado continuarán en vigor durante un período adicional de diez años después de la fecha de terminación.

Lo que se intenta con esto es que el inversor goce de estabilidad para su inversión durante el mayor tiempo posible. Un caso paradigmático sobre la aplicación de estas cláusulas es el de Bolivia. Este país denunció el Convenio del CIADI en mayo de 2007, lo cual implicó que dejaba de reconocer su jurisdicción en el caso de demandas de las transnacionales. Sin embargo, posterior a esa fecha, se presentaron frente al CIADI seis demandas interpuestas por transnacionales cuyas filiales bolivianas fueron nacionalizadas por el gobierno de Evo Morales. Estas demandas son legales en los términos planteados por los TBI y por el Tratado del CIADI. ${ }^{38}$

Por último, veamos las cláusulas que dan forma a los mecanismos de solución de controversias. Los tratados bilaterales remiten en su mayoría a una instancia supranacional para la defensa de los intereses de los inversores externos en relación con los actos de una de las partes. Como hemos señalado, esto es llamado prórroga de jurisdicción; los Estados-nación ceden su

\footnotetext{
${ }^{38}$ Según el artículo 71 del CIADI, la denuncia por parte de un país producirá efecto recién seis meses después de recibir dicha notificación. El artículo 72 agrega que la denuncia no afectará derechos y obligaciones de un Estado o de sus nacionales, nacidos del consentimiento a la jurisdicción del CIADI y dados con anterioridad al recibo de dicha notificación por el depositario. En el caso boliviano, el Estado denunció el Tratado del ciadi el 1 de mayo de 2007, cumpliéndose los seis meses el 1 de noviembre de ese año. El 12 de octubre, dos semanas antes de que se venciera el plazo, la empresa de telecomunicaciones ETI presentó una denuncia contra Bolivia en el CIADI.
} 
soberanía en justicia frente a las demandas de estos inversores. En caso de controversia, la mayoría de los tratados bilaterales plantea que exista una instancia de "diálogo amistoso" entre el inversor y la parte afectada. Pero si pasado un cierto tiempo la controversia no ha sido saldada, entonces el inversor tiene la posibilidad de acudir a la justicia nacional de la parte o, si lo prefiriese, recurrir al arbitraje internacional. El TBI entre Argentina y Panamá dice en su artículo noveno:

Si la controversia no hubiera podido ser solucionada en el término de seis meses a partir del momento en que fue planteada por una $\mathrm{u}$ otra de las Partes, podrá ser sometida, a pedido del inversor: a los tribunales competentes de la Parte Contratante en cuyo territorio se realizó la inversión, o bien, al arbitraje internacional en las condiciones descriptas en el apartado (3) de este Artículo.

Como dijimos en el apartado anterior, el CIADI muestra la tendencia a la protección de la movilidad del capital. En los momentos en que tienen que garantizar su ganancia, las empresas se olvidan de su bandera de origen y aprovechan las mejores condiciones contractuales que les ofrece el variopinto de tratados. Esto se expuso con claridad en el caso de Bechtel versus Bolivia. Esta empresa transnacional con base en los Estados Unidos había demandado a Bolivia porque rescindió el contrato de su subsidiaria "Aguas del Tunari" tras la llamada guerra del Agua, protagonizada por el pueblo boliviano en el año 2000. Pero Bechtel realizó diversas operatorias de compra y venta de sus acciones con accionistas menores, vía las islas Caimán, para pasar a ser de "nacionalidad holandesa", beneficiándose así del твг entre Bolivia y Holanda. El tribunal arbitral conformado para esta demanda aceptó sin problemas la nacionalidad holandesa ficticia de Aguas del Tunari, argumentando que, mismo si se trataba de un movimiento inusual, la migración era admisible conforme a la legislación de las islas Caimán. ${ }^{39}$

\section{CONCLUSIONES}

En este artículo reconstruimos teóricamente el modo en que opera la búsqueda de certezas por parte del capital, centrándonos para ello en los TBI. Intentamos mostrar cómo se entiende la libertad en el marco del nuevo momento del comando del capital-dinero, que es la libertad del capital. Los tratados internacionales firmados son expresión de esa tendencia. Efectivamente, el actual patrón de acumulación requiere de un avanzado entramado legal que proteja las inversiones.

${ }^{39}$ Teitelbaum, Alejandro, op. cit. 
En ese marco, los Estados nacionales compiten entre sí para atraer los capitales, o quedan en la difícil situación de no poder controlar la lucha de clases al interior de sus territorios. Este tipo de protecciones no hubieran sido posibles en el periodo keynesiano de la segunda posguerra, donde lo central era la fortaleza del mercado interno, y los Estados operaban como reguladores de la lucha del trabajo a partir de garantizar el flujo descendente de dinero hacia los trabajadores (vía salarios). Estos tratados ahora cristalizan la libertad del capital a través de cláusulas como la de Trato Nacional, prohibiendo los requisitos de desempeño del capital y anulando la posibilidad de casi cualquier política pública de los Estados que afecte la inversión privada extranjera.

En este artículo, ejemplificamos la competencia interestatal no sólo a partir de los países más industrializados, que sin duda están muy interesados en proteger las inversiones de las empresas con cede en sus territorios (por ello son los que tienen mayor cantidad de TBI firmados a nivel global). Ningún Estado escapa de la presión por parte del capital para que otorguen certezas a las inversiones, justamente porque Estado y mercado no son cosas separadas, sino esferas unidas-en-la-separación de la acumulación capitalista, ambos con el mismo objetivo: la reducción del trabajo a fuerza de trabajo, es decir, a mercancía.

A su vez, el modo en que opera la protección de las inversiones asegura que los Estados que intentan un camino diferente, motivados por el modo en que se ha desplegado la lucha al interior de sus territorios, sufran las consecuencias de las nuevas prerrogativas del capital. Sin embargo, esta acción no ha significado que los capitales vuelen lejos del país que denuncia los твI o el CIADI. De hecho, la mayor parte de las empresas que denunciaron a estados como Venezuela, Ecuador o Bolivia no se fueron de sus territorios. Pero sí implica que se impone una disciplina en términos de las arcas estatales, generando una nueva deuda externa de la cual el país debería hacerse cargo en algún momento. De lo contrario, se somete a sufrir consecuencias en los foros internacionales ${ }^{40} \mathrm{o}$ a ver dificultado el acceso al financiamiento externo, vía Fondo Monetario Internacional o Banco Mundial.

Algo queda en claro a partir de lo expresado en estas páginas: romper la tendencia librecambista implica mucho más que la aplicación de políticas "progresistas" realizadas hoy por algunos Estados. La garantía a la libre circulación del capital es la premisa para el nuevo comando (inestable) del capital

\footnotetext{
${ }^{40}$ Por ejemplo, España buscó que Argentina fuera aislada al interior del G-20 (e incluso expulsada) si no pagaba en tiempo y forma la expropiación de las acciones adueñadas por la empresa española REPSOL en la petrolera YPF. Se amparaba para dicha acción en el TBI firmado entre Argentina y España, argumentando que la Argentina "no respeta la seguridad jurídica" "'Rajoy buscará 'aislar' a la Argentina en el G-20 por la expropiación a Repsol, $L a$ Voz. Disponible en http://www.lavoz.com.ar/noticias/politica/ rajoy-buscara-aislar-argentina-g-20-expropiacion-repsol). Finalmente, REPSOL retiró la demanda del CIADI al negociar la indemnización por la expropiación con el Estado.
} 
sobre el trabajo (el comando del capital-dinero). La disciplina de mercado se impone sobre todos los países, sean abiertamente progresistas o neoliberales. Esto es el resultado de la reconfiguración de la lucha de clases tras la derrota de las organizaciones sindicales y sociales de los años setenta y ochenta. El modo en que pueda lograrse una nueva configuración (o la ruptura de la sociedad de clases) no depende de los Estados, sino del desenvolvimiento de la lucha entre capital y trabajo en cada territorio nacional. 


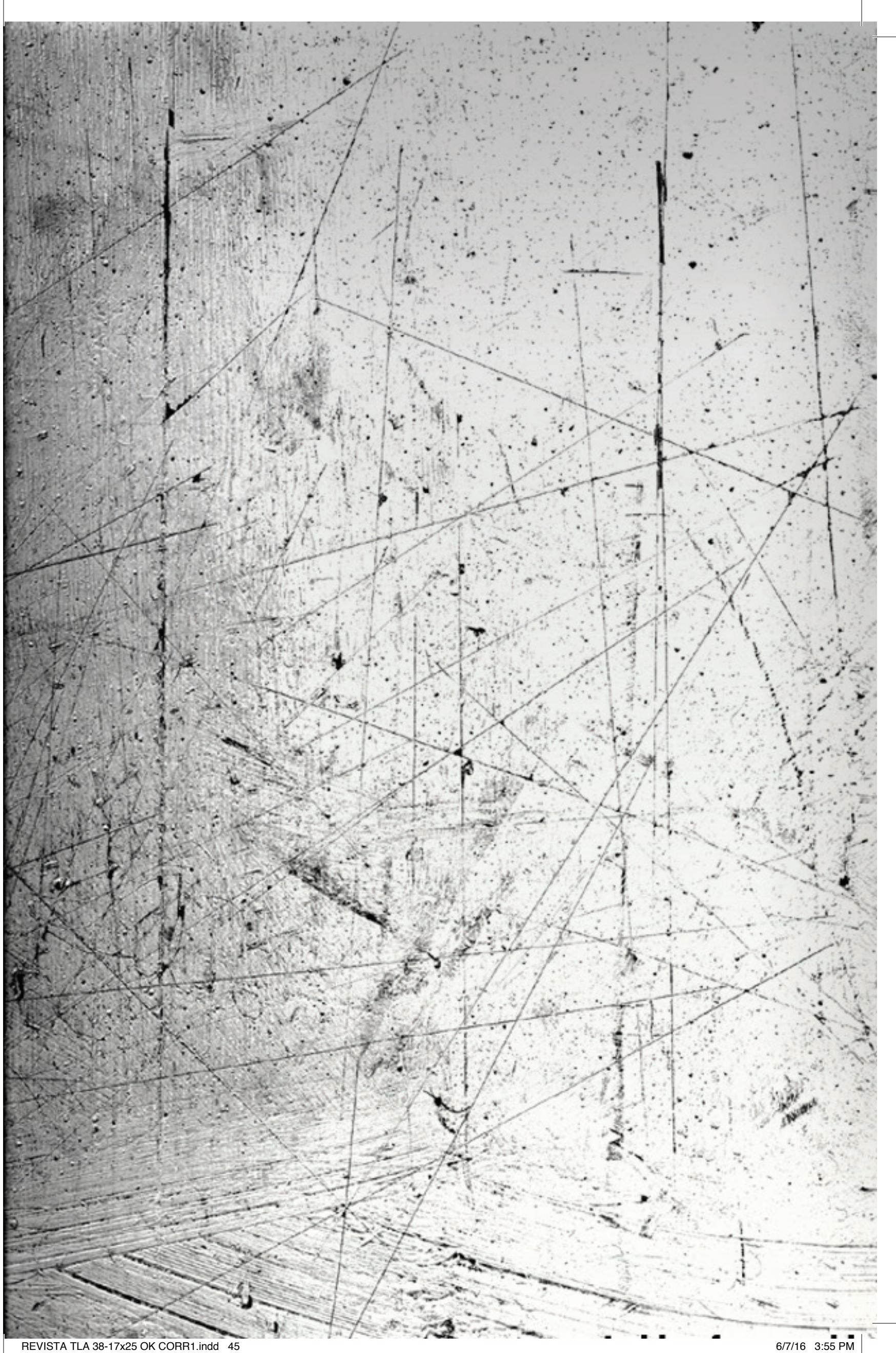

